\title{
CULTIVO DE CEPAS DE LEVADURAS DE SUELO TRUMAO EN «VINAZA»
}

\author{
(Cultivation of yeast strains of the trumao soil in «vinasse»)
}

Eduardo Valenzuela, $\mathbf{F}^{1 *}$., Paola Díaz, N1., Camila Aranda, G1․, Osar Martínez, V'. Roberto Godoy B²

1. Instituto de Bioquímica y Microbiología, Facultad de Ciencias, Universidad Austral de Chile. Casilla 167. Fono 632221296. 2. Instituto de Ciencias Ambientales y Evolutivas, Facultad de Ciencias, Universidad Austral de Chile, Valdivia, Chile.

*Autor para correspondencia:evalenzu@uach.cl

RECIBIDO: 31 de Octubre de 2014 APROBAD0: 26 de Noviembre de 2014

LOS AUTORES DECLARAN NO TENER CONFLICTO DE INTERESES

Palabras claves: «vinaza», levaduras de suelo trumao, fosforo, proteínas, lípidos, peso seco.

Key Word: «vinasse», yeast volcanic ash soil (Hapludans), phosphorus, proteins, fat, dry weigh.

\section{RESUMEN}

30 cepas de levaduras aisladas desde un suelo trumao (Hapludans) usado como pradera en rotación, se cultivaron individualmente $\left(100 \mu \mathrm{l}=\mathrm{a} 10^{2}\right.$ ufc de levaduras $/ \mathrm{mL}$ ) en matraces con $50 \mathrm{~mL}$ de «vinaza», estos fueron incubados en un agitador orbital a 150 rpm, $23^{\circ} \mathrm{C}$ por 5 días, luego de la incubación el contenido de cada matraz se centrifugo a $3.500 \mathrm{rpm}$ por 20 min., a los pellet obtenidos se les determino: el peso seco (PS); fosforo total (FT) por digestión ácida y posterior lectura a $400 \mathrm{~nm}$; proteínas totales (PT) por colorimetría Biuret a $595 \mathrm{~nm}$ y lípidos totales (LT) mediante el método colorimétrico de la sulfo-fosfo vainillina a $520 \mathrm{~nm}$. Las 30 cepas de levaduras crecieron en la vinaza. El mayor PS lo registro la cepa 25 (331 g de levadura $\mathrm{L}^{-1}$ de «vinaza»). FT lo registro la cepa 28 (4,8 $\mathrm{mg} \mathrm{g}^{-1}$ de levadura seca). PT lo registro la cepa 24 (25,90 $\mathrm{mg} \mathrm{g}^{-1}$ de levadura seca) y LT lo registro la cepa 18 (287,4 $\mathrm{mg} \mathrm{g}^{-1}$ de levadura seca).

\section{INTRODUCCIÓN}

Las levaduras son hongos pertenecientes al Reino Fungi, abundantes en la naturaleza que viven

\section{ABSTRACT}

Thirty strains of yeast isolated from a volcanic ash soil (Hapludans), used as pasture rotation, were individually cultured $\left(100 \mu \mathrm{l}=10^{2} \mathrm{cfu}\right.$ of yeast cells $\mathrm{mL}^{-1}$ ) in flasks with $50 \mathrm{~mL}$ of «vinasse», these were incubated at $23^{\circ} \mathrm{C}$ for 5 day, after incubation the contents of each flask was centrifuged at $3500 \mathrm{rpm}$ for $20 \mathrm{~min}$, the pellet obtained was determined: dry weight (DW); total phosphorus (FT) by acid digestion and later reading at $400 \mathrm{~nm}$; total protein (TP) by Biuret at $595 \mathrm{~nm}$ and total lipid (TL) by the colorimetric method of the sulfo-phospho-vanillin at $520 \mathrm{~nm}$. The Thirty strains of yeast grown on vinasse. The best DW, was determined for strain 25 (331 g yeast $\mathrm{L}^{-1}$ «vinasse»). FT was determined for strain 28 (4,8 mg $\mathrm{g}^{-1}$ dry yeast). TP was determined for strain 24 (25, $90 \mathrm{mg} \mathrm{g}^{-1}$ dry yeast) and TL was determined for strain18 (287, $4 \mathrm{mg} \mathrm{g}^{-1}$ dry yeast).

en una serie de reservorios (agua, suelo, hojas, flores, frutos, piel, insectos, etc.). El suelo es el último reservorio para el desarrollo de ciertas especies de levaduras (Wuczkowski y Prillinger., 2004), 
encontrándose una amplia diversidad de levaduras filogenéticamente no relacionadas, incluyendo especies como Saccharomyces cerevisiae (asociada a bebidas fermentadas), y que forman parte de la comunidad microbiana del suelo. La diversidad de levaduras en el suelo ha sido examinada en diferentes partes del mundo, desde suelos tropicales hasta antárticos (Slavikova y Vadkertiova., 2000). La presencia de las levaduras en el suelo está dado por diversas características tales como: tipo de suelo, régimen de lluvias, clima y perturbación antrópica. Con respecto a este último, existen estudios que demuestran como la actividad humana influye sobre la diversidad y estructuras comunitarias de las levaduras en el suelo, así Slavikova y Vadkertiova (2003), evaluaron la ocurrencia de levaduras en suelo con distintos tipos de cultivo (maíz, remolacha y papas) y los compararon con suelos no labrados, determinaron que en suelos labrados existe una disminución de la población de levaduras y asocian este fenómeno al uso de pesticidas y fungicidas. De manera similar Yurkov et al., (2012), analizaron la respuesta en lo que respecta a la diversidad de levaduras en suelos con diferentes tipos de manejo, el análisis de abundancia de especie y estructura de las comunidades reveló un fuerte efecto a largo plazo, en el cambio de bosque por pastizales se determinó que en suelos de pastizales albergan predominantemente levaduras Ascomycetes a diferencia de los suelos de bosque en donde la estructura de las comunidades de levaduras es más heterogénea.

En el sur de Chile, los suelos trumaos constituyen cerca del $60 \%$ de los suelos arables del país, se encuentran bajo un amplio rango de usos, desde sistemas prístinos hasta uso intensivo (Dörner et al., 2009). Se sabe que el tipo de manejo que se le da al suelo repercute de algún modo sobre las comunidades microbianas, así, el estudio realizado por Huygens et al., (2011) en suelos de la zona centro sur de Chile, sobre cómo influye la intensidad del manejo del suelo sobre las comunidades microbianas (bacterianas y fúngicas), se determinó que existe una variación de estas comunidades en eventos de secado y humectación del suelo, indicando que los hongos presentan mayor tolerancia al estrés hídrico. Zagal (2002) por su parte evaluó las comunidades microbianas en suelo de origen volcánico bajo distinto manejo agronómico, determinó que el índice de actividad microbiana fue uno de los parámetro más sensible al manejo agronómico versus la variación del carbono orgánico.

Con respecto a comunidades de levaduras en suelos, Mestre et al., (2011), sugieren que la participación de las levaduras en el ciclo de Carbono esta dado por su relación en la degradación de la hemicelulosa y que también pueden estar asociadas a procesos de agregación del suelo, por la abundante recuperación de levaduras encapsuladas que tuvieron en sus experimentos. Además, encontraron que las levaduras Basidiomycetes fueron las predominantes en todas las fracciones de suelo recuperadas (Noreste de la Patagonia Argentina). En Chile existe escaza información acerca de las comunidades de levaduras de suelo trumao, sin embargo existen algunos referentes a hongos filamentosos, como el de Valenzuela et al., (2000) donde se identificaron y determinaron sus potenciales enzimáticos en suelos trumaos sometidos a diversos tipos de manejo agroforestales en la X Región y otro de Valenzuela y Martínez (2007), sobre actualización del registro de levaduras citadas en Chile.

Por otra parte, la identificación de desechos industriales con potencialidad de ser utilizado como sustrato para el cultivo de levaduras es primordial a la hora de querer masificarlas con distintos fines, tales como: alimenticios, abonos orgánicos agrícolas 0 forestales, bioremediación, etc. (Fathi et al., 2011; Liu et al., 2012). En este sentido, en Valdivia - Chile, una industria genera un potencial desecho que denominan localmente «vinaza» (luego del cultivo de la levadura Sacharomyces) la evaluación química ha revelado que posee distintos azucares y fuentes de nitrógeno, esta «vinasa» fue utilizado con éxito por Hott (2012), para cultivar levaduras de pino y palmera con la finalidad de obtener etanol, la presente propuesta es utilizar la «vinaza» para cultivar levaduras aisladas desde una pradera permanente de suelo trumao, con la finalidad de formular un biofertilizante a base de levaduras.

\section{MATERIAL Y MÉTODOS}

a) Características químicas de la «vinaza»: el sustrato 
«vinaza» utilizado para cultivar las levaduras fue proporcionada por la empresa de Levaduras Collico, Valdivia - Chile, mediante métodos estandarizados de la empresa se determinaron los siguientes parámetros: contenido de agua; sólidos solubles totales; densidad; pH; proteína total; materia grasa; carbohidratos solubles; glucosa; fructosa y sacarosa.

b) Recolección de muestras de suelo: tres muestras de suelo trumao (Hapludand), cada una de ellas de $200 \mathrm{~g}$, fueron recolectadas desde una pradera en rotación (profundidad de $0-20 \mathrm{~cm}$ ), ubicada en la comuna de San José de la Mariquina en el predio de Don Klaus Prehn (UTM: 673,75 E; 56625,5 N., Cuadrante H18).

c) Aislamiento y cultivo de cepas de levaduras: $10 \mathrm{~g}$ de la muestra de suelo a analizar se depositaron en un matraz de $300 \mathrm{~mL}$, se agregaron $100 \mathrm{~mL}$ de agua destilada estéril, la mezcla obtenida se homogeneizó mecánicamente en un agitador orbital a $150 \mathrm{rpm}$ por 20 min., luego se realizaron diluciones seriadas hasta $10^{6}$, cada dilución se sembró independientemente, para ello $1 \mathrm{~mL}$ de la dilución respectiva fue depositado en una placa Petri estéril y vacía, a la placa se le agregaron $0,3 \mathrm{~mL}$ de una mezcla de antibióticos (penicilina y estreptomicina 1:1) y $15 \mathrm{~mL}$ de agar Sabouraud, la placa se roto para mezclar, se dejo solidificar y finalmente se incubo a $23^{\circ} \mathrm{C}$ por 5 días. Las colonias de levaduras que se formaron fueron repicadas en placas con agar Sabouraud sin antibióticos e incubadas a $23^{\circ} \mathrm{C}$ por 5 días, tras lo cual se realizaron preparaciones en fresco (usando agua destilada como liquido de montaje) para corroborar que se tratara de levaduras y determinar su pureza. Así se lograron rescatar 30 cepas de levaduras.

d) Cultivo de cepas de levaduras en «vinaza»: cada cepa de levadura se cultivo por triplicado, para ello se procedió de la siguiente forma. En un matraz que contenía $50 \mathrm{~mL}$ de «vinaza» previamente esterilizada en autoclave $\left(121^{\circ} \mathrm{C}\right.$ por 15 min.) se inocularon 100 $\mu \mathrm{l}$ (= a $10^{2}$ ufc de levaduras $/ \mathrm{mL}$ ) de la cepa de levadura en estudio, los matraces se incubaron en un agitador orbital a $150 \mathrm{rpm}, 23^{\circ} \mathrm{C}$ por 5 días.

e) Determinación de parámetros de crecimiento: como medidas del crecimiento de las levaduras cultivadas en la «vinaza» se determinaron: (1) el Peso Seco (PS), cumplido los 5 días de agitación el contenido del matraz se deposito en tubos centrifugas, se centrifugaron a $3.500 \mathrm{rpm}$ por $20 \mathrm{~min}$., los pellet obtenidos se rescataron del tubo, se depositaron en un papel aluminio (previamente pesado) y se pesaron en una balanza analítica, obteniendo así el peso fresco, luego se secaron en un horno a $70^{\circ} \mathrm{C}$, hasta obtener peso constante (aprox. 48 horas), el PS se calculo, restando el seco obtenido al peso fresco inicial del pellet. (2) Fósforo Total (FT) se determino por digestión ácida y lectura de la absorbancia (A) a $400 \mathrm{~nm}$. (3) Proteínas Totales (PT), por colorimetría Biuret lectura de (A) a $595 \mathrm{~nm}$ y Lípidos Totales (LT), mediante el método colorimétrico de la sulfo-fosfo vainillina lectura de (A) a $520 \mathrm{~nm}$. Todas las determinaciones se realizaron por triplicado.

f) Análisis estadístico: a los valores matemáticos de los diferentes parámetros se les determinó la media y desviación estándar. Posteriormente se evaluaron los supuestos de normalidad y homocedasticidad de varianza. Para el tratamiento estadístico se realizo un análisis de varianza (ANDEVA), aplicando test de Tukey $(P \leq 0,05)$. El tratamiento estadístico fue realizado con el programa Statistica 7.0.

\section{RESULTADOS Y DISCUSION}

De acuerdo a Lezcano y Mora (2005), se define vinaza como «Líquido espeso que queda después de la fermentación y/o destilación con un color café oscuro", el residuo utilizado comparte el color oscuro pero no proviene de la destilación o fermentación, proviene del cultivo de levadura para panificación. En la Tabla 1, se muestran los principales parámetros químicos determinados en la «vinaza» utilizada para el cultivo de cepas de levaduras, destacan, la cantidad de carbohidratos solubles $8 \%$, la proteína total 2,6 \% y la ausencia de sacarosa $0,0 \%$. Respecto a los constituyentes de la vinaza según Silva et al., (2011) estos varían en gran proporción, pues depende del origen de la vinaza, así por ejemplo la vinaza obtenida después de la producción de bioetanol y cachaza que fue usada posteriormente en sus experimentos, contenía: 0,18 \% de azucares totales, proteínas 0,33 $\%$ y sacarosa $0,04 \%$., los dos primero parámetros son inferiores a los determinados en la vinaza utilizada en 
la presente investigación y la presencia de sacarosa supera ampliamente este parámetro, pues no fue registrada en la «vinaza» de la presente investigación. Por su parte García y Rojas (2006), señalan que la vinaza de la caña de azúcar contiene una variedad de nutrientes vegetales, así, posee un $18 \%$ de carbono oxidable, un $5,9 \%$ de proteína totales, una serie de ácidos orgánicos y azúcares entre ellas sacarosa 0,21 $\%$, los dos primero parámetros son superiores a los determinados en la vinaza utilizada en la presente investigación y la presencia de sacarosa difiere pues la vinaza de la presente investigación carece de ella. Como se puede deducir de los trabajos antes citados la vinaza va a depender de la materia prima que la origino y la concentración de sólidos totales que contenga. En la presente investigación se utilizo el residuo que queda después del cultivo de levadura comercial, denominado «vinaza», esta por poseer sólidos totales $10^{\circ}$ Brix, correspondería a una vinaza diluida.

Tabla 1. Caracterización química de «vinaza» de la empresa Levaduras Collico Valdivia - Chile

\begin{tabular}{l|c}
\hline \multicolumn{1}{c|}{$\begin{array}{c}\text { Parámetros determinados en } \\
\text { "vinaza" }\end{array}$} & Cantidad \\
Contenido de agua & $94,1 \mathrm{~g} \mathrm{~L}^{-1}$ \\
Sólidos solubles totales & $10^{\circ} \mathrm{Brix}^{-1,047 \mathrm{~g} \mathrm{cc}^{-1}}$ \\
Densidad & 6,6 \\
$\mathrm{pH}$ & $2,6 \%$ \\
Proteína total & $0,004 \%$ \\
Materia grasa & $8,0 \%$ \\
Carbohidratos solubles & $1,8 \%$ \\
Glucosa & $1,8 \%$ \\
Fructosa & $0,0 \%$ \\
Sacarosa & \\
\hline
\end{tabular}

En la Tabla 2, se muestran los resultados promedios de los parámetros evaluados: Peso Seco (PS), Fósforo Total (FT), Proteínas Totales (PT) y Lípidos Totales (LT), de las levaduras cultivadas en «vinaza». Con respecto a el PS, este vario entre 168 (cepa 7) a $3314 \mathrm{mg}$ de levadura $\mathrm{L}^{-1}$ de «vinaza», este último vaIor fue obtenido con la cepa 25, el análisis estadístico indica que existen diferencias significativas ( $\mathrm{Pd}$ » 0,05$)$ entre algunas cepas de levaduras. En lo que respecta a FT, esta vario entre 0,3 (cepa 29) a $4,8 \mathrm{mg} \mathrm{g}^{-1}$ de levadura seca, este último valor fue determinado para la cepa 28, el análisis estadístico indica que existen diferencias significativas $(P d$ d 0,05$)$ entre algunas cepas de levaduras. Referente a PT, estas variaron entre 7,80 (cepa 12) a 25,90 $\mathrm{mg} \mathrm{g}^{-1}$ de levadura seca, este último valor fue determinado para la cepa 24 , el análisis estadístico indica que existen diferencias significativas ( $\mathrm{Pd}$ » 0,05) entre algunas cepas de levaduras. Finalmente los LT variaron entre 63,9 (cepa 16) a $287,4 \mathrm{mg} \mathrm{g}^{-1}$ de levadura seca, este último valor fue determinado para la cepa 18, el análisis estadístico indica que existen diferencias significativas ( $P \mathrm{~d} » 0,05)$ entre algunas cepas de levaduras.

Tauk (1982), utilizo vinaza y melaza sin y con modificaciones químicas para el cultivo de especies de Candida, la autora propuso 13 medios de cultivos, algunos modificados con distintas fuentes de nitrógeno, fósforo, sales minerales y $\mathrm{pH}$, en cada medio cultivo un especie distinta de levadura del género Candida (en total 7 especies) y se midieron distintos parámetros. En el medio de cultivo denominado vinaza sola a pH 5.0 todas las cepas de Candida crecieron (al igual que en la presente investigación) y el mayor peso seco obtenido fue 4,6 $\mathrm{g} / \mathrm{L}$ para Candida utilis y el menor peso seco fue 1,4 $\mathrm{g} / \mathrm{L}$ para Candida guilliermondii, en la presente investigación el mayor peso seco fue de $3314 \mathrm{mg} / \mathrm{L}$ $(=3,314 \mathrm{~g} / \mathrm{L})$ y el menor $168 \mathrm{mg} / \mathrm{L}(=0,168 \mathrm{~g} / \mathrm{L})$, siendo inferior al obtenido por Tauk (1982), esta misma autora señala que el peso seco más alto fue registrado para Candida krusei con 8,3 g/L en vinaza adicionada al $0,03 \%$ de $\mathrm{K}_{2} \mathrm{SO}_{4}$ a pH 5.0 y no se registro crecimiento para Candida tropicalis en vinaza más $0,05 \%(\mathrm{NH} 4)_{2} \mathrm{SO}_{4}$ y vinaza más $0,03 \% \mathrm{~K}_{2} \mathrm{SO}_{4}$. En lo que respecta a producción de proteína en vinaza sola Tauk (1982), determino un máximo de 45,8 \% para C. utilis y un mínimo de $20,1 \%$ para C. guilliermondii, Por su parte Silva et al., (2011) determinaron diversos parámetros químicos en cultivos de cepas de Saccharomyces cerevisiae y Candida parapsilosis realizados en vinaza luego de la obtención de bioetanol y la elaboración de cachaza, los autores señalan que la biomasa obtenida vario entre 0.7 y $15.0 \mathrm{~g} \mathrm{~L}^{-1}$, ambos valores obtenidos para cepas de S. cerevisiae, en lo que respecta a proteínas determinaron como promedio un $56,25 \%$, siendo el porcentaje menor $44,68 \%$ 
Tabla 2. Resultados promedios de peso seco, fosforo total, proteínas totales y lípidos totales determinados en cepas de levaduras cultivadas en «vinaza» de la empresa Levaduras Collico Valdivia - Chile.

\begin{tabular}{|c|c|c|c|c|}
\hline \multirow{2}{*}{$\begin{array}{c}\text { CEPA DE } \\
\text { LEVADURA }\end{array}$} & \multicolumn{4}{|c|}{ PARAMETROS ( $\mathrm{mg} \mathrm{g}^{-1}$ de levadura seca) } \\
\hline & $\begin{array}{c}\text { PESO SECO } \\
\text { (mg L-1 de melaza) }\end{array}$ & $\begin{array}{l}\text { FOSFORO } \\
\text { TOTAL }\end{array}$ & $\begin{array}{l}\text { PROTEINAS } \\
\text { TOTALES }\end{array}$ & $\begin{array}{l}\text { LIPIDOS } \\
\text { TOTALES }\end{array}$ \\
\hline 1 & $1926 c$ & $3,6 b$ & $8,80 \mathrm{c}$ & $161,0 b$ \\
\hline 2 & $439 d$ & $1,0 \mathrm{~d}$ & $15,80 b$ & $256,8 \mathrm{a}$ \\
\hline 3 & $1680 \mathrm{c}$ & $1,7 d$ & $20,50 \mathrm{a}$ & $199,4 b$ \\
\hline 4 & $1485 \mathrm{c}$ & $2,7 \mathrm{c}$ & $10,80 b$ & $158,2 b$ \\
\hline 5 & $439 d$ & $2,9 c$ & $12,10 b$ & $114,1 b$ \\
\hline 6 & $1633 \mathrm{c}$ & $1,7 d$ & $12,20 b$ & $258,9 a$ \\
\hline 7 & $168 \mathrm{~d}$ & $1,3 d$ & $12,10 \mathrm{~b}$ & $261,0 \mathrm{a}$ \\
\hline 8 & $1540 \mathrm{c}$ & $2,4 c$ & $9,20 \mathrm{c}$ & $128,5 b$ \\
\hline 9 & $346 d$ & $1,6 \mathrm{~d}$ & $17,80 \mathrm{~b}$ & $217,2 \mathrm{a}$ \\
\hline 10 & $1566 \mathrm{c}$ & $3,2 b$ & $13,50 b$ & $240,0 \mathrm{a}$ \\
\hline 11 & $2175 b$ & $2,3 c$ & $10,60 b$ & $130,7 b$ \\
\hline 12 & $2425 b$ & $2,6 \mathrm{c}$ & $7,80 \mathrm{c}$ & $248,7 \mathrm{a}$ \\
\hline 13 & $1967 \mathrm{c}$ & $2,1 \mathrm{c}$ & $17,60 \mathrm{~b}$ & $160,6 b$ \\
\hline 14 & $841 d$ & $3,9 b$ & $17,60 \mathrm{~b}$ & $261,0 \mathrm{a}$ \\
\hline 15 & $994 d$ & $3,4 b$ & $8,10 \mathrm{c}$ & $148,7 b$ \\
\hline 16 & $1311 \mathrm{c}$ & $1,1 \mathrm{~d}$ & $11,00 \mathrm{~b}$ & $63,9 \mathrm{c}$ \\
\hline 17 & $1844 \mathrm{c}$ & $1,0 d$ & $10,70 b$ & $211,0 \mathrm{a}$ \\
\hline 18 & $2065 b$ & $2,4 \mathrm{c}$ & $16,40 b$ & $287,4 a$ \\
\hline 19 & $1945 c$ & $2,5 c$ & $14,20 \mathrm{~b}$ & $131,7 b$ \\
\hline 20 & $1566 \mathrm{c}$ & $2,0 \mathrm{c}$ & $15,20 b$ & $187,5 b$ \\
\hline 21 & $2237 b$ & $3,1 b$ & $23,20 \mathrm{a}$ & 72,70 \\
\hline 22 & $2357 b$ & $1,3 d$ & $16,60 b$ & $132,9 b$ \\
\hline 23 & $2782 b$ & $1,0 d$ & $23,00 \mathrm{a}$ & $143,1 b$ \\
\hline 24 & $1831 \mathrm{c}$ & $0,9 e$ & $25,90 \mathrm{a}$ & $176,2 b$ \\
\hline 25 & $3314 a$ & $0,4 \mathrm{e}$ & $13,40 b$ & $97,3 \mathrm{c}$ \\
\hline 26 & $2042 b$ & $0,8 \mathrm{e}$ & $20,80 \mathrm{a}$ & $162,6 b$ \\
\hline 27 & $2067 b$ & $2,3 c$ & $13,20 b$ & $187,9 b$ \\
\hline 28 & $2261 b$ & $4,8 \mathrm{a}$ & $12,50 b$ & $128,8 b$ \\
\hline 29 & $2858 b$ & $0,3 e$ & $22,60 \mathrm{a}$ & $212,6 a$ \\
\hline 30 & $2170 \mathrm{~b}$ & $1,6 \mathrm{~d}$ & $17,40 \mathrm{~b}$ & $127,0 \mathrm{~b}$ \\
\hline
\end{tabular}

Valores con letras minúsculas distintas en la misma columna difieren estadísticamente en forma significativa $(P$ d» 0,05).

y el mayor $68,43 \%$ ambos determinados para $S$. cerevisiae cepa UFLA CA271. Por otra parte, Ferrer et al., (2004) determinaron la producción de proteínas usando la cepa de $C$. utilis (ATCC 9256) y S. cerevisiae (ATCC 26603) cultivadas en melaza de caña de azúcar, determinaron un 53,0 y un $47,8 \%$ respectivamente. Gutiérrez y Gómez (2008), determinaron la producción de proteína total para cepas distintas de $S$. cerevisiae y C. utilis también en bagazo de caña (melaza), la cual fue de 45 y $49 \%$ respectivamente. En la presente investigación el máximo de proteína registrado fue de $25,90 \mathrm{mg} \mathrm{g}^{-1}$ de levadura seca $(=25,9 \%)$ para la cepa 24 y el mínimo fue de $7,8 \mathrm{mg} \mathrm{g}^{-1}$ de levadura seca $(=7,8 \%)$ para la cepa 12 , estos valores son 
inferiores a los señalados por los autores anteriormente citados y consideramos se deben a la composición química de la «vinaza» usada, autores como García y Rojas (2006), señalan critica la relación carbono : nitrógeno $(\mathrm{C}: \mathrm{N})$, esta debe ser idealmente de $10: 1$.

Referente al fosforo Tauk (1982), señala que obtuvo un $5,1 \%$ para Candida membranaefaciens y un $1,5 \%$ para $C$. utilis, por su parte Ferrer et al., (2004) determinaron un $1,6 \%$ y un $1,8 \%$ de fósforo para $S$. cerevisiae $C$. utilis, en la presente investigación la cepa 29 registro la menor cantidad de fósforo $0,3 \mathrm{mg} \mathrm{g}^{-1}$ de levadura seca $(=0,3 \%)$, por su parte, la cepa 28 registro la mayor cantidad de fósforo $4,8 \mathrm{mg} \mathrm{g}^{-1}$ de levadura seca $(=4,8 \%)$, este último valor se asemeja más al obtenido por Tauk (1982) y es superior a los determinados por Ferrer et al., (2004). Finalmente en lo que respecta a los lípidos totales Rodríguez et al., (2011) usaron destilados de vinaza para cultivar $C$. utilis para ser utilizada como alimento para aves de corral, señalan que $C$. utilis contiene un $22,33 \mathrm{~g} / \mathrm{kg}$ de lípidos totales. Rodríguez et al., (2012), al realizar el cultivo de $C$. utilis en destilados de vinaza obtenida del destilado de caña de azúcar registraron $23.66 \mathrm{~g} /$ $\mathrm{kg}$ de lípidos totales y $729 \mathrm{mg} / 100 \mathrm{~g}$ ácido linoleico. Además señalan que el $35,24 \%$ son ácidos grasos saturados, un 29,68 \% son ácidos grasos monoinsaturados y $35,08 \%$ son ácidos grasos poliinsaturados. Por su parte Harder et al., (2013) utilizaron diversos residuos mezclados con vinaza para cultivar cepas de levaduras (Cryptococcus laurentii 11; Cryptococcus sp.nov3; Lipomyces starkeyi JAL 425; Lipomyces starkeyi JAL572; Lipomyces starkeyi JAL 576; Lipomyces starkeyi JAL 581; Rhodotorula graminis CBS 2826; Tricosporon sp.nov.1 y Yarrowia lipolytica) con la finalidad de obtener lípidos para ser utilizados en la producción de biofuels. El mayor porcentaje de lípidos totales fue 29,69 \% para la cepa de $R$. graminis CBS 2826 y el menos porcentaje de lípidos totales fue $5,36 \%$ para Y. lipolytica, en la presente investigación las cantidades de lípidos totales caen dentro de los rangos señalados por este último autor, aun más la menor cantidad $\left(63,9 \mathrm{mg} \mathrm{g}^{-1}\right.$ de levadura seca determinada en la cepa 16) es superior a la determinada por Harder et al. (2013) para Y. lipolytica. Pero difieren de los valores determinados por Rodríguez et al., (2012), estas diferencias se deberían a la composición química de la «vinaza» utilizada en la presente investigación.

\section{CONCLUSIONES}

La «vinaza» generada por la planta de Levaduras - Collico, puede ser utilizada como un sustrato aceptable para el cultivo de levaduras aisladas desde una pradera en rotación de un suelo trumao y los resultados de los distintos parámetros utilizados como medida de crecimiento, son similares a los indicados en la literatura para otras levaduras cultivadas en residuos similares.

Las levaduras cultivadas en la "vinaza» ensayada, por poseer una buena cantidad de proteínas, fósforo y lípidos podrían ser utilizadas para distintos fines, tales como: suplemento proteico para alimentos, obtención de lípidos y formulación de biofertilizantes.

\section{AGRADECIMIENTOS}

Al proyecto FONDECYT 1141066.

\section{REFERENCIAS}

Dörner, J., Dec, D., Peng, X. y Horn, R. (2009). Efecto del cambio de uso en la estabilidad de la estructura y la función de los poros de un andisol (typic hapludand) del sur de chile. Revista de la ciencia del suelo y nutrición vegetal, 9:190-209.

Fatih, M. y Balat M. Biowastes-to-biofuels. (2011).Energy Conversion and Management, 52:1815-1828.
Ferrer, J., Davaliillo, Y., Chandler, C., Páez, Z y Ramones, E. (2004). Producción de proteína microbiana a partir de los desechos del procesamiento de la caña de azúcar (bagacillo). Arch. Latinoam. Prod. Anim. 12(2): 59-65.

García, A. y Rojas, C. (2006). Posibilidades de uso de la vinaza en la Agricultura de acuerdo con su modo de acción en los suelos. www.tecnicana.org/pdf/2006/ 
tec_v10_no17_2006_p3-13.pdf

Gutiérrez, L. y Gómez, A. (2008). Determinación de proteína total de Candida utilis y Sacharomyces cerevisiae en bagazo de caña. Revista Lasallista de Investigación, 5 (1): 61-64.

Harder, M., Delabio, A., Cazassa, S., Remedio, R., Pires, J., Monteiro, T. y Arthur, V. (2013). Lipid production by Yarrowia lipolytica for biofuels. Materials and processes for energy: communicating current research and technological developments. Ed. A. Mendez-Vilas. Publisher: Formatex Research Center, USA. $274-278$ pp.

Hott, E. (2012). Obtención de etanol, producido por levaduras de pino y palmera. Tesis de Químico Farmacéutico, Facultad de Ciencias, Universidad Austral de Chile. Valdivia 37 p.

Huygens, D., Schouppe, J., Roobroeck D., Alvarez, M., Balocchie, O., Valenzuela, E., Pinochet, D. y Boeck, P. (2011). Drying-rewetting effects on N cycling in grassland soils of varying microbial community composition and management intensity in south central Chile. Applied Soil Ecology, 48:270279.

Lezcano, P. y Mora, L. (2005). Las vinazas de destilería de alcohol. Contaminación ambiental 0 tratamiento para evitarlo. Conferencia 7. VIII encuentro de nutrición y producción de animales monogástricos. www.avpa.ula.ve/eventos/viii_encuentro.../ conferencia-7.pdf

Liu, W., Wanga, Y., Yu, Z. y Bao, J. (2012). Simultaneous saccharification and microbial lipid fermentation of corn stover by oleaginous yeast Trichosporon cutaneum.Bioresource Technology, 118: 13-18.

Mestre, M., Rosa, C., Safar, S., Libkind D. y Fontenla S. (2011).Yeast communities associated with the bulksoil, rhizosphere and ectomycorrhizosphere of a Nothofagus pumilio forest in northwestern Patagonia, Argentina. Microbiology ecology, 78: 531-541.

Rodríguez, B., Mora, L., Oliveira, D., Euler, A., Lara, L. y Lezcano, P. (2011). Chemical composition and nutritive value of torula yeast (Candida utilis), grown on distiller's vinasse, for poultry feeding. Cuban J. Agric. Sci. 45:261- 265.

Rodríguez, B., Iben, Ch., Valdivié, M. y Martínez, M. (2012). Profile of fatty acids from torula yeast (Candida utilis) grown on distiller's vinasse. Technical note. Cuban Journal of Agricultural Science, 46:199 $-201$.

Silva, C., Arcuri, S., Campos, C., Vilela, D., Alves, J. y Schwan, R. (2011). Using the residue of spirit production and bio-ethanol for protein production by yeasts. Waste Management 31: 108-114.

Slavikova, E. y Vadkertiova, R. (2000). The occurrence of yeasts in the forest soils. J. Basic Microbiol, 40: 207-212.

Slavikova, E. y Vadkertiova, R. (2003). The diversity of yeasts in the agricultural soil. J. Basic Microbiol, 43:430-436.

Valenzuela, E., Carias P., Pinochet, D. y Polette, M. (2000). Nuevas citas de hongos aislados de suelo trumao sometido a diferentes manejos agro-forestales en la X Región de Chile. Boletín Micológico 15: 107111.

Valenzuela, E. \& Martinez, 0. 2007. Actualizacion del registro de levaduras citadas en Chile. Boletín Micológico 22: 81 - 93.

Wuczkowski M. y Prillinger H. (2004). Molecular identification of yeasts from soils of the alluvial forest national park along the river Danube downstream of Vienna, Austria ("National park donauauen"). Microbiological Research, 159: 263-275.

Yurkov A., Kemler M. y Begerow D. (2012). Assessment of yeast diversity in soils under different management regimes. Fungal ecology, 5: 24-35

Zagal, E., Vidal, I., Rodríguez, N. y Quezada, L.(2002). Actividad microbiana en un suelo de origen volcánico bajo distinto manejo agronómico. Agricultura Técnica, 62(2): 297-309. 